\title{
AC 2010-10: DEVELOPMENT OF A FOUR-STORY ELEVATOR SYSTEM FOR TEACHING MOTION CONTROL CONCEPT WITH PROGRAMMABLE LOGIC CONTROLLER
}

Shiyoung Lee, Pennsylvania State University, Berks 


\title{
Development of a Four-Story Elevator System for Teaching Motion Control Concept with Programmable Logic Controller
}

\begin{abstract}
The motion control and the programmable logic controller (PLC) are essential sub-modules in the industry automation systems. The integration of motion control teaching components into a course has been successful for the past two years. Practicing programming with a PLC trainer provides a limited range of real world experiences which usually involves various motion control components. Therefore, various assignments using input/output (I/O) devices could be given to students to exercise development of ladder logic diagrams. But more dynamic applications with motion control components are necessary to train and prepare students for the real world. The development of the PLC controlled four-story elevator is the final project assignment for students in the advanced PLC course. This final project requires the following tasks: the development of interfacing software for the human machine interface (HMI) terminal, the design of a hoist using a stepper motor, the implementation of a position-sensing mechanism, the completion of a ladder logic diagram for entire elevator control and the development of a miniature four-story frame that will enclose a carriage. In this paper, various PLC-based motion control topics, which are necessary to complete the final project, are introduced and the implementation details of the PLC controlled four-story elevator is discussed.
\end{abstract}

\section{Introduction}

This paper introduces the recently applied motion control project - a PLC-controlled four-story elevator system - to the advanced PLC course. Penn State Berks offers a year-long PLC course for both EET (Electrical Engineering Technology) and EMET (Electro-Mechanical Engineering Technology) students. The fundamentals of the programmable logic controls (EET275) are taught in the spring semester and the advanced topics (EMET430) are covered in the fall semester.

The advanced course was designed to enable students to exercise many skills that they can directly apply to solve real world problems. In order to practice the various skills that students acquired through classes and lab exercises, the development of a PLC-controlled four-story elevator system was assigned to the students as the final project.

At the beginning of the advanced course, students learn about the PanelView operator terminal and the PanelBuilder software to design control panel applications for the PV550 terminal ${ }^{1,2}$. The lab assignments are based on the user manuals from the manufacturer and customized descriptive problems. Four major motor types - induction motor, brushed and brushless dc motors, and stepper motor - are introduced. The characteristics of these motors and application methods are emphasized in the classes and labs.

Programming with an industrial control trainer (ICT) from Bytronic Inc. is the second exercise. The purpose of this exercise is to become familiar with various motion control components such as the permanent magnet dc motor (PMDC) and linear and rotary solenoids ${ }^{3}$. The experiments with the proximity sensors, both capacitive and inductive types, and the photo sensors are also 
included in this laboratory exercise. The ICT lab provides numerous topics that students could apply to real world problem solving. The topics include: control of permanent magnet dc motor, linear and rotary solenoids, and interfacing various sensors. In order to interface sensors to the PLC, scaling and mechanical adjustment techniques are required. Design of proper timing for the overall system control is very important in writing a working ladder logic diagram.

The stepper motor control is given to the class as the next laboratory assignment. The students will learn how to use the special stepper motor drive module. The final design project is given to student groups of three or four members each. Each group builds a scale model of the four-level elevator system using a stepper motor as the prime mover and necessary sensors. The major assessment criteria for the four-story elevator development project are the application of HMI terminal for the elevator control and accurate position control of a carriage using a stepper motor. The Ultraware class provides an opportunity for students to program and run the digital ac brushless servo system, which is widely used in industry ${ }^{6,7}$, and 8 .

The PLC lab at Penn State Berks is equipped with six SLC500 PLC training stations, each with a 10-slot modular chassis from Rockwell Automation. The details of the modules installed will be explained in the ICT section.

The topics of the class and lab for the advanced PLC course are listed in Table 1.

Table 1. Proposed topics for the advanced PLC class and lab

\begin{tabular}{|c|l|l|}
\multicolumn{2}{|c}{ Class } \\
Week & \multicolumn{1}{|c|}{ Topics } \\
\hline 1 & PanelView / Communications & PanelView \\
\hline 2 & PanelView / Communications (continue) & PanelView (continue) \\
\hline 3 & Motor Drives & Programming with ICT \\
\hline 4 & Motor Drives (continue) & Programming with ICT (continue) \\
\hline 5 & Motor Drives (continue) & Stepper Motor Drive \\
\hline 6 & Motor Drives (continue) & Stepper Motor Drive \\
\hline 7 & PID & Stepper Motor Drive (continue) \\
\hline 8 & PID (continue) & Oven Temperature Control \\
\hline 9 & PID (continue) & Oven Temperature Control (continue) \\
\hline 10 & Ultraware & Automated PLC Controlled Lighting \\
\hline 11 & Ultraware (continue) & Automated PLC Controlled Lighting (continue) \\
\hline 12 & Fuzzy Logic & Motor Control for Waste Water Treatment \\
\hline 13 & Fuzzy Logic (continue) & Motor Control for Waste Water Treatment (continue) \\
\hline
\end{tabular}

The summaries of a couple of major teaching components embedded into the advanced course are listed below. The purpose of these topics is to introduce students to a broad range of hardware and software components for the motion control applications with SLC500 PLC. The final elevator development project is the compilation of all the skills that students have learned from both introductory and advanced PLC courses. 


\section{PanelView - PV550 HMI Terminal and Panelbuilder32}

The main objective of this teaching component is to provide students with the opportunity to learn about the HMI terminal, which is widely used in the industries. Since the PLC lab at Penn State Berks is equipped with the PV550 monochrome terminal, the class focuses on how to use PanelBuilder32 software with the SLC500 PLC. A couple of exercise problems are given to the class to practice using the PanelBuilder32 software.

The students will learn to control their ladder logic diagram through not only $\mathrm{I} / \mathrm{O}$ devices on the PLC training station, but also through the PV550 HMI terminal for future motion control projects. Designing a PV550 screen is one of the requirements for the final elevator project. The four-story elevator can operate with both pushbutton switches on the SLC500 trainer and the PV550 HMI terminal.

\section{ICT System}

The lab exercises with the ICT system provide students with techniques for parts detection, sorting, and assembly. The ICT from Bytronics is designed to sort an aluminum peg from a plastic ring, then assemble these two components and check for correct assembly. Initially those components are randomly placed on the chain conveyor. The chain conveyor moves them to the assembly chute. Then the plastic components are detected by the sort area infrared (IR) sensor and ejected by a linear solenoid down the plastic ring hopper. In the meantime, the aluminum peg remains on the conveyor and goes down to the belt conveyor through the feeder chute. The plastic ring hopper is positioned above the belt conveyor in order to engage the peg with the hole in the ring. The inductive- and capacitive-type proximity sensors and IR sensors are positioned, along with the belt conveyor, to check for correct assembly. The properly assembled parts proceed into the finished parts tray, while incomplete assemblies are rejected by a linear solenoid into the recycle bin.

Two I/O modules, 1746-OW8 and 1746-IB16 are used to control the ICT through SLC500 PLC. The details of the modules installed are listed in Table 2 below.

Table 2. Details of SLC500 Ten-Slot Modular System

\begin{tabular}{|c|l|l|}
\hline Chassis Slot Location & Part Number & \multicolumn{1}{c|}{ Description } \\
\hline 0 & $1747-$ L541 & SLC 5/04 CPU - 16K Mem. OS401 \\
\hline 1 & $1746-$ OA16 & 16-Input (TRIAC) 100/240 VAC \\
\hline 2 & $1747-S D N$ & DeviceNet Scanner \\
\hline 3 & $1746-$ IB16 & 16-Input (SINK) 24 VDC \\
\hline 4 & $1746-O B 16$ & 16-Output (TRANS-SRC) 24 VDC \\
\hline 5 & $1746-$ IB16 & 16-Input (SINK) 24 VDC \\
\hline 6 & $1746-O B 16$ & 16-Output (TRANS-SRC) 24 VDC \\
\hline 7 & $1746-O W 8$ & 8- Output (RLY) 240VAC \\
\hline 8 & $1746-$ IB16 & 16-Input (SINK) 24 VDC \\
\hline 9 & $1746-N T 4$ & Analog 4 Ch Thermocouple Input \\
\hline
\end{tabular}

The concepts of interfacing sensors and control of motors in the ICT lab exercises offer very important skills for the students to complete the final project. 


\section{Stepper Motor Drive}

There are numerous stepper motor drive applications in the automation and process industries. The shaft of the stepper motor can be held in any fixed position, providing precise positioning control. The stepper motor can rotate in both clockwise (CW) and counter-clockwise (CCW) directions. An electronic circuit - indexer or translator with a power amplifier - is essential for the stepper motor to drive it.

The objective of this teaching component is to provide various real world techniques for the drive stepper motor to students. The STP-DRV-4035 micro stepping drive from Automation Direct $^{4}$ and the 1746-HSTP1stepper controller module ${ }^{5}$ are used for this lab. The experimental setup of the stepper motor drive and a sample PV550 screen are shown in Figure 1.

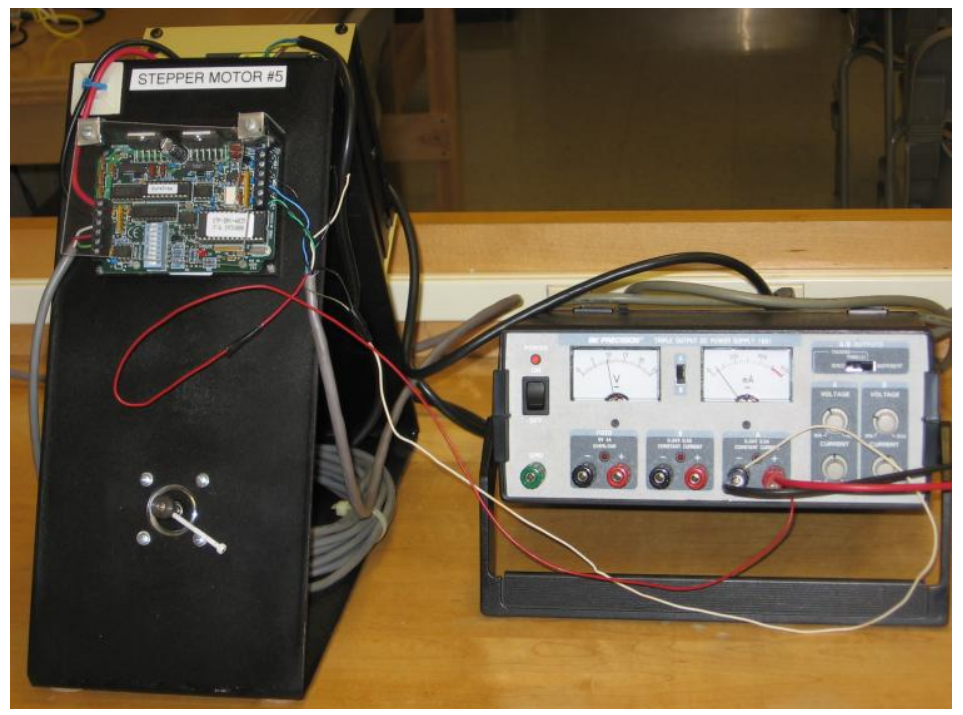

(a) Stepper motor drive setup

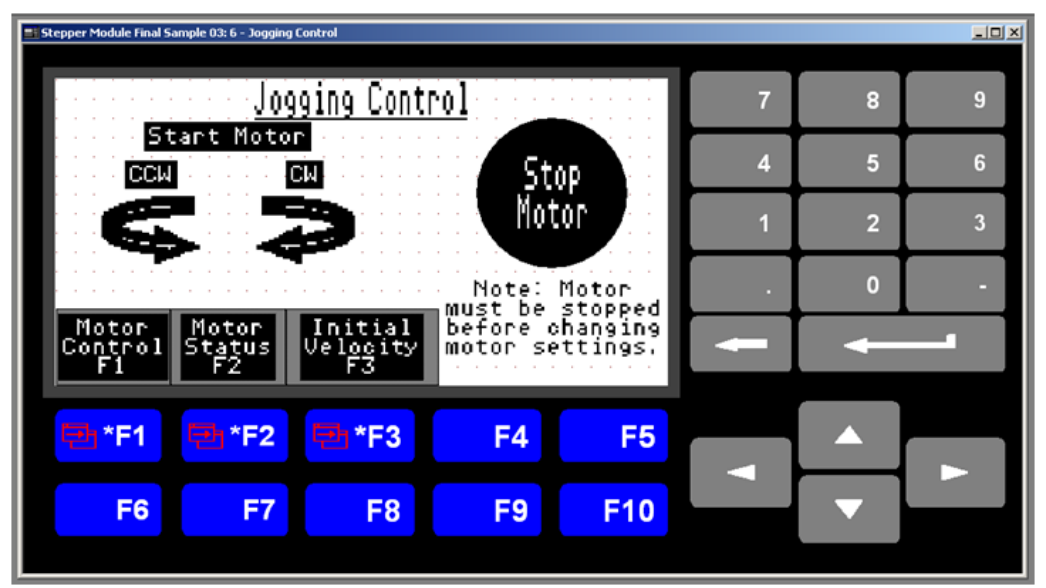

(b) Sample PV550 screen developed to control a stepper motor

Figure 1. Experimental setup of the stepper motor drive and PV550 screen 
In order to control the stepper motor properly, the I/O data tables of the stepper controller module must be configured ${ }^{5}$. The module can be configured to determine which inputs are used, the active level of inputs used, and whether a quadrature encoder is used. In addition, the module should be configured to select whether the output of the module is a pulse train with direction command or CW and CCW pulse trains; it must also select configuration mode or command mode.

Since the stepper motor is used as the prime mover for the elevator, the lab exercise requiring the design of a ladder logic diagram to control the stepper motor is very important to the completion of the final project.

\section{Final Project}

At the beginning of the course, the importance of the final project is addressed. In the previous semester, the final project was a group effort, with topics proposed by the student and then carefully selected by the instructor. Due to the limitation of the hardware availability on the PLC trainer, the previous projects are merely static simulations of various real world applications.

The proposed motion control enhanced final project is to design and build a simple four-story elevator system which is controlled by SLC500 PLC. Three groups with a maximum of four students per group will design and build their own four-story elevator systems. The prime mover of the elevator system is the stepper motor. The same types of stepper motor, translator, and position sensors are given to each group.

The requirement of the elevator system is limited to only the basic operation of the elevator, such as moving up and down and stopping at each level, with simulated operations of opening and closing the elevator door with lamp indicators. The students may learn from this project about group work, project scheduling, selection and interfacing of sensors, scaling, and the application of stepper drives.

The preliminary design report is due during the third week of the class. This report includes the design consideration, implementation procedure and schedule of the project, and task distribution between members. Two progress reports are required to evaluate the performance of the group. Every report is graded and instructor's comments are added. The final report and demonstration of the developed elevator will occur near the end of the semester to complete the project.

The assigned I/O addresses for the final project are listed in Tables 3 below.

Table 3. Assignment of I/O addresses based on the SLC500 trainer

(a) Inside of the carriage

\begin{tabular}{|l|l|l|l|}
\hline Input & & Output & \\
\hline I:3.0/8 & First Floor Request & O:4.0/8 & First Floor Requested PL \\
\hline I:3.0/9 & Second Floor Request & O:4.0/9 & Second Floor Requested PL \\
\hline I:3.0/10 & Third Floor Request & O:4.0/10 & Third Floor Requested PL \\
\hline I:3.0/11 & Fourth Floor Request & O:4.0/11 & Fourth Floor Requested PL \\
\hline I:3.0/12 & Hold Door Open & O:6.0 & Floor Indicator LED Display \\
\hline
\end{tabular}


Table 3. Assignment of I/O addresses on the trainer (continue)

(b) Outside of the elevator

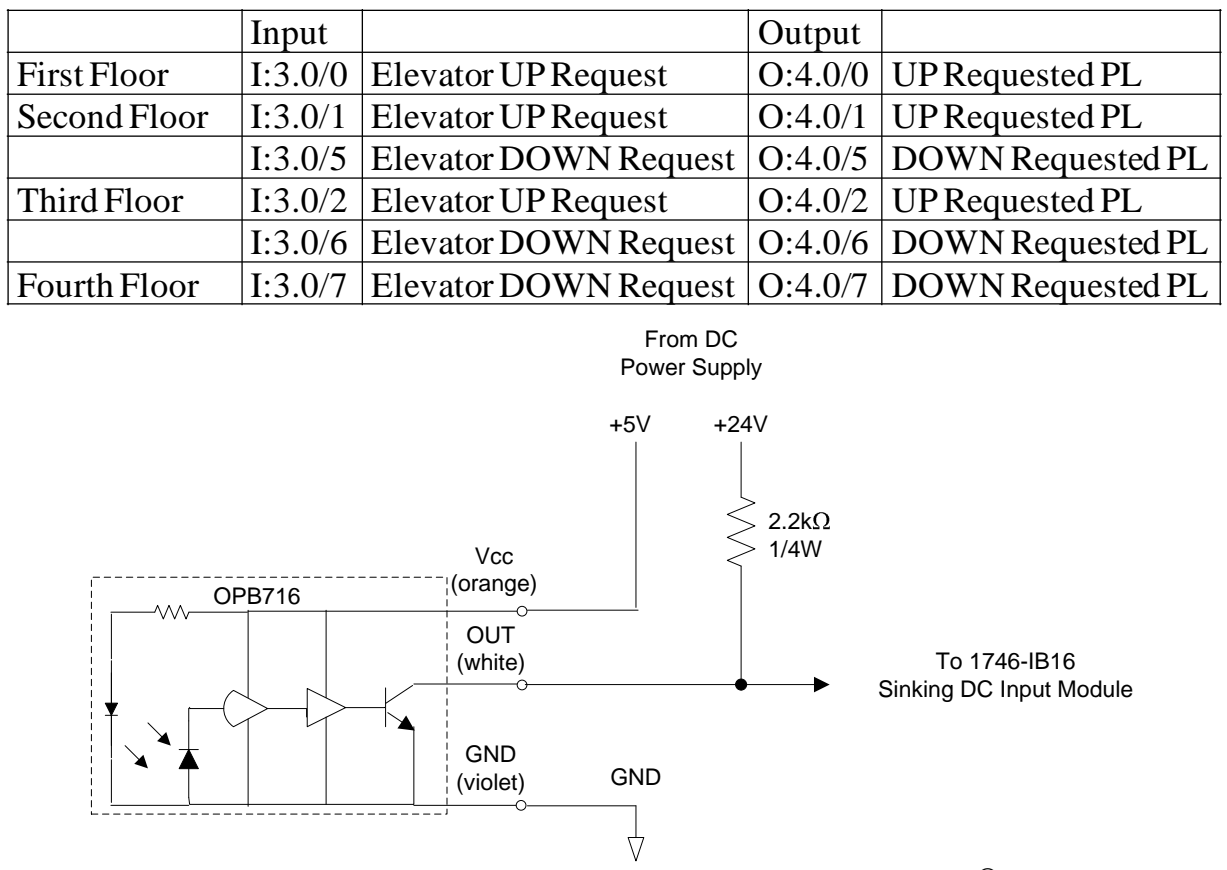

Figure 2. Basic connection diagram for the Photologic ${ }^{\circledR}$ reflective object sensor from OPTEK Technology

The common position sensor is the OPB716Z Photologic ${ }^{\circledR}$ reflective object sensor from OPTEK Technology. Six reflective object sensors are used to sense the position of carriage. Two mechanical limit switches sense the top and bottom of the elevator frame. The basic connection diagram is shown in Figure 2. An example of a student-developed connection diagram of the eight sensors and the 1746-IB16 digital input module is shown in Figure 3.

The elevator display LED should show each floor number as a hundred. For example, the second floor will be displayed as 200 on the LED. It takes the elevator five seconds to move between floors, and the LED should also display the floor number appropriately. For example, as the elevator is moving up from the second floor to the third floor, the LED display will show 201, $202, \ldots, 298,299$, and 300.

Finally, the elevator door needs to be able to open and close. It takes the door two and a half seconds to open and close. While the door is in the process of opening, a green pilot lamp (O:4/12) should flash. When the door is fully open, the lamp should change to be stably on. On the other hand, while the door is in the process of closing, the other green pilot lamp (O:4/13) should flash. When the door is fully closed, the lamp should be solidly on.

Safety concerns, such as the elevator being able to move with the door open, will be up to the group's design preferences. A student-developed PV550 screen to control the four-story elevator is shown in Figure 4, and the relevant tag assignment is listed in Figure 5. 


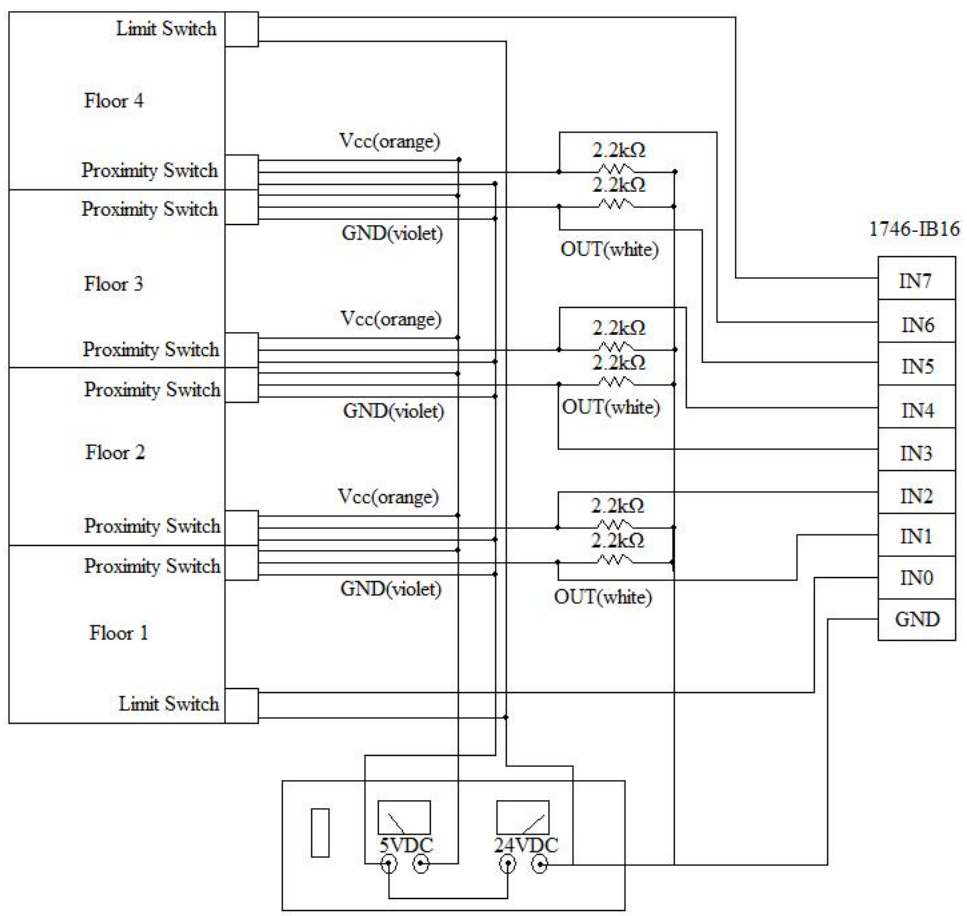

Figure 3. Example of student-developed connection diagram between eight position sensors and the 1746-IB16 digital module



Figure 4. Student-developed PV550 screen to control a four-story elevator

\begin{tabular}{|c|c|c|c|c|c|c|c|}
\hline \multicolumn{8}{|c|}{ elevator: Tag Editor } \\
\hline \multicolumn{3}{|c|}{ 象田 目 } & \multicolumn{5}{|c|}{ 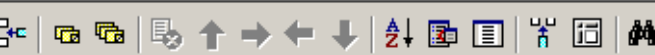 } \\
\hline & Tag llame & Data Type & Array Size & Description & Hode llame & Address & Initial Value \\
\hline 1 & Door_open & Bit & 1 & Door open & LC_1 & 83:7/4 & 0 \\
\hline 2 & Floor_1 & Bit & 1 & Floor 1 & LC_1 & $83: 70$ & 0 \\
\hline 3 & Floor_2 & Bit & 1 & Floor 2 & LC_1 & $\mathrm{B} 3: 7 M$ & 0 \\
\hline 4 & Floor_3 & Bit & 1 & Floor 3 & LC_1 & $83: 7 / 2$ & 0 \\
\hline 5 & Floor_4 & Bit & 1 & Floor 4 & LC_1 & $83: 7 / 3$ & 0 \\
\hline
\end{tabular}

Figure 5. Tag assignments for the student-developed PV550 screen to control a four-story elevator 


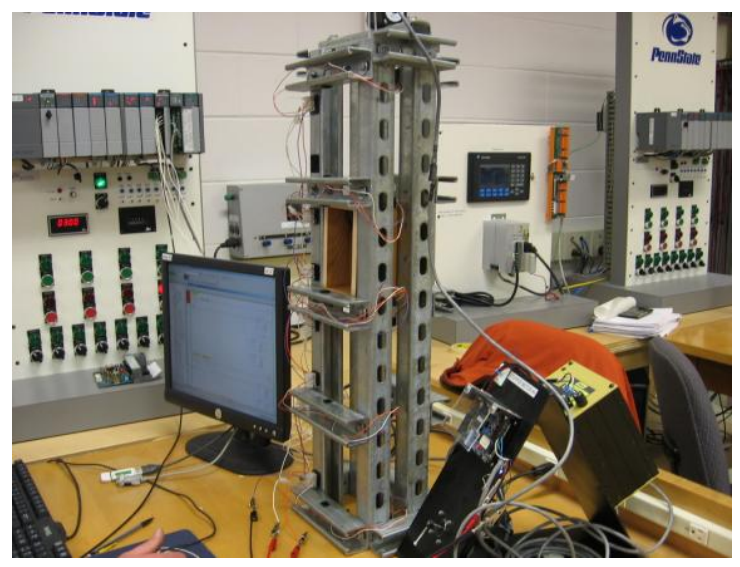

(a) Framed with U-channel and reflective object sensors

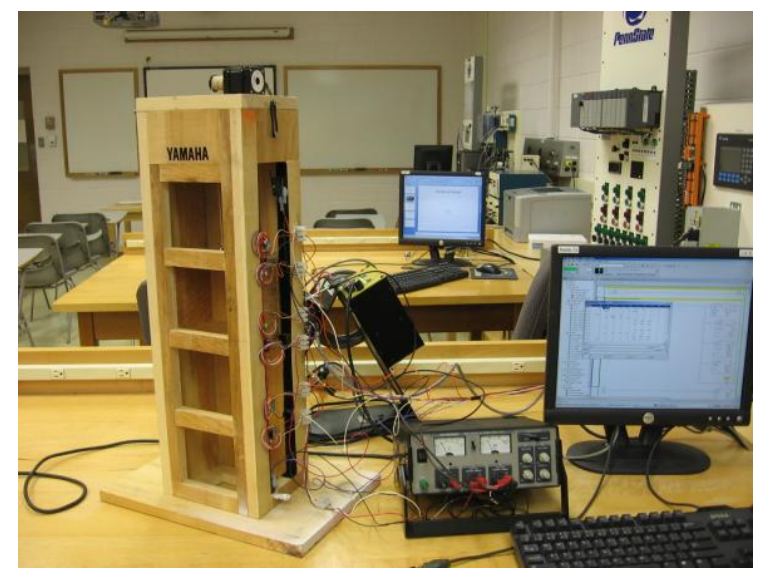

(b) Wood frame with reflective object sensors

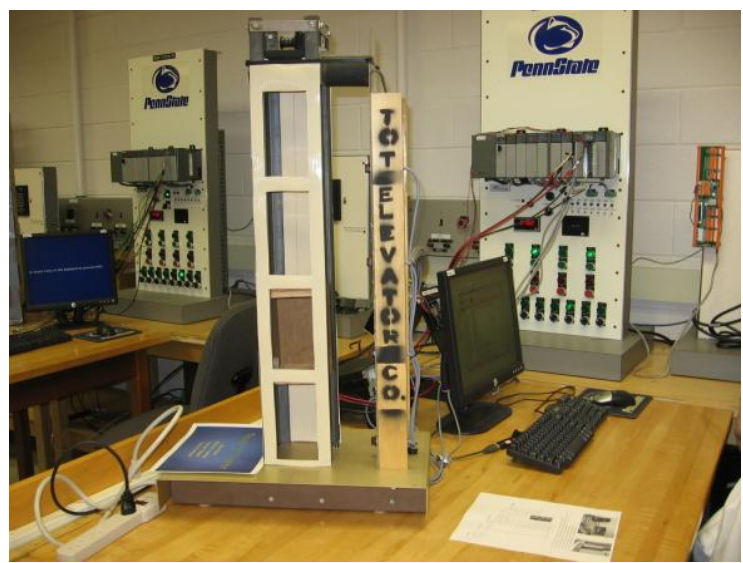

(c) Mix with steel and wood frame and through hole beam sensors

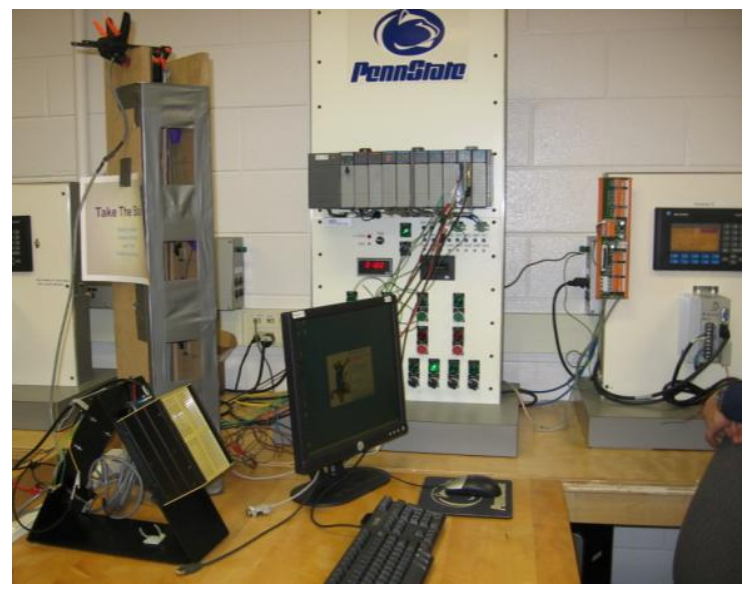

(d) Wood frame with reflective object sensors

Figure 6. Examples of developed four-story elevators by students

The assorted samples of the student-designed and -built four-story elevator systems are shown in Figure 6. An old version has through-hole beam sensors as shown in Figure 6(c), but the second revision uses only reflective object sensors. Because the beam sensor is located outside the carriage and the reflector is installed inside of the carriage, a hole is required on the carriage to enable the beam light to reach the reflector.

\section{Conclusion}

The newly applied motion control enhanced four-story elevator system development project provides students with not only fundamental theories but also hands-on experience. The various hands-on labs were designed to develop essential technical skills which are applicable to real world motion control applications. The major skills students could develop through the newly developed advanced PLC course include scaling of analog I/O signals along with the selection of right sensors, creation and use of I/O data tables, and the use of advanced PLC instructions, etc. 
In addition, team work ethics, time management skills, and organizational skills are acquired by the completion of the project. The students expressed very optimistic opinions on the newly developed motion teaching components and the four-story elevator development project; they stated they enjoyed challenging assignments. An attachment of a small permanent magnet dc motor to the carriage to make the door close and open will be a great additional topic for the future project.

\section{Acknowledgement}

The author would like to express deep appreciation to Jeff Wike, Lab Manager, and the students of the EMET430 Advanced PLC course during fall semesters at the Penn State Berks.

\section{Bibliography}

1. Rockwell Automation, "Getting Started with PanelBuilder Software User Manual," Publication 2711-6.2February 1997.

2. Rockwell Automation, "PanelBuilder32 Application Development Software for PanelView Standard Terminals Quick Start Manual,” Publication 2711-QS003C-EN-P-March 2002.

3. Bytronic International Inc., "Documentation for the Bytronic Industrial Control Trainer," Version 3.15, 1996.

4. Automation Direct, "SureStep Stepping Systems User Manual," Revision B, Manual Number STP-SYS-M, March 2007.

5. Rockwell Automation, "Stepper Controller Module User Manual," Publication 999-121-December 1999.

6. Rockwell Automation, "Ultraware User Manual," Release 1.5, Publication 2098-UM001F-EN-E-June 2002.

7. Rockwell Automation, "Ultra3000 Digital Servo Drives Integration Manual," Publication 2098-IN005CEN-P-March 2008.

8. Rockwell Automation, "IMC110 Termination Panel Installation Data," Publication 1746-2.31-October 1990.

9. Rockwell Automation, "SLC Servo Control Module User Manual," Publication 1746-6.1.2-July 2000. 